\title{
Shire gobbles up Lumena and its fatty liver pills
}

Shire, now part of AbbVie, paid \$260 million cash upfront for small biotech Lumena to get its hands on its two liver treatments. Lumena's most advanced prospect is LM001, a treatment currently in phase 2 to treat cholestatic liver diseases, the other compound is LUM002, scheduled to enter phase 2 to treat nonalcoholic steatohepatitis (NASH), a form of fatty liver. The deal, which closed in May, reflects "big pharma's growing interest in this area," says Alan Carr, a biotech analyst at Needham and Co. in New York.

NASH awareness is at an all-time high. Because this liver inflammation is caused mostly by fat accumulation, numbers are predicted to soar in line with the obesity epidemic-and industry wants in. Just how badly became clear earlier this year when Intercept Pharmaceuticals of New York stopped its phase $2 \mathrm{NASH}$ trial with INT-747 because of high efficacy (Nat. Biotechnol. 32, 207, 2014). The biotech saw its stock shoot up by $580 \%$ over two days. Halting a trial early because of effectiveness, "almost never happens," says Carr. "The price explosion is a measure of investor excitement about this indication."

Incidence of this once rare disease has more than doubled since 2005. Liver symptoms are similar to those caused by alcohol consumption, though in NASH, the liver becomes inflamed from fat deposits, rather than from alcohol, leading to cirrhosis and ultimately liver failure. NASH is the fastest growing cause of liver transplants in the US, and there are no approved drugs to treat it. Analysts estimate peak sales of a NASH drug could reach \$3-4 billion annually.

At least seven drugs are currently in development to treat NASH. Each targets the disease in different ways (Table 1). "There is a whole spectrum of physiology that you could attack in this disease," says Alfred P. Spada, CSO of Conatus Pharmaceuticals of San Diego. Conatus' drug is targeted at the early stages to stop disease

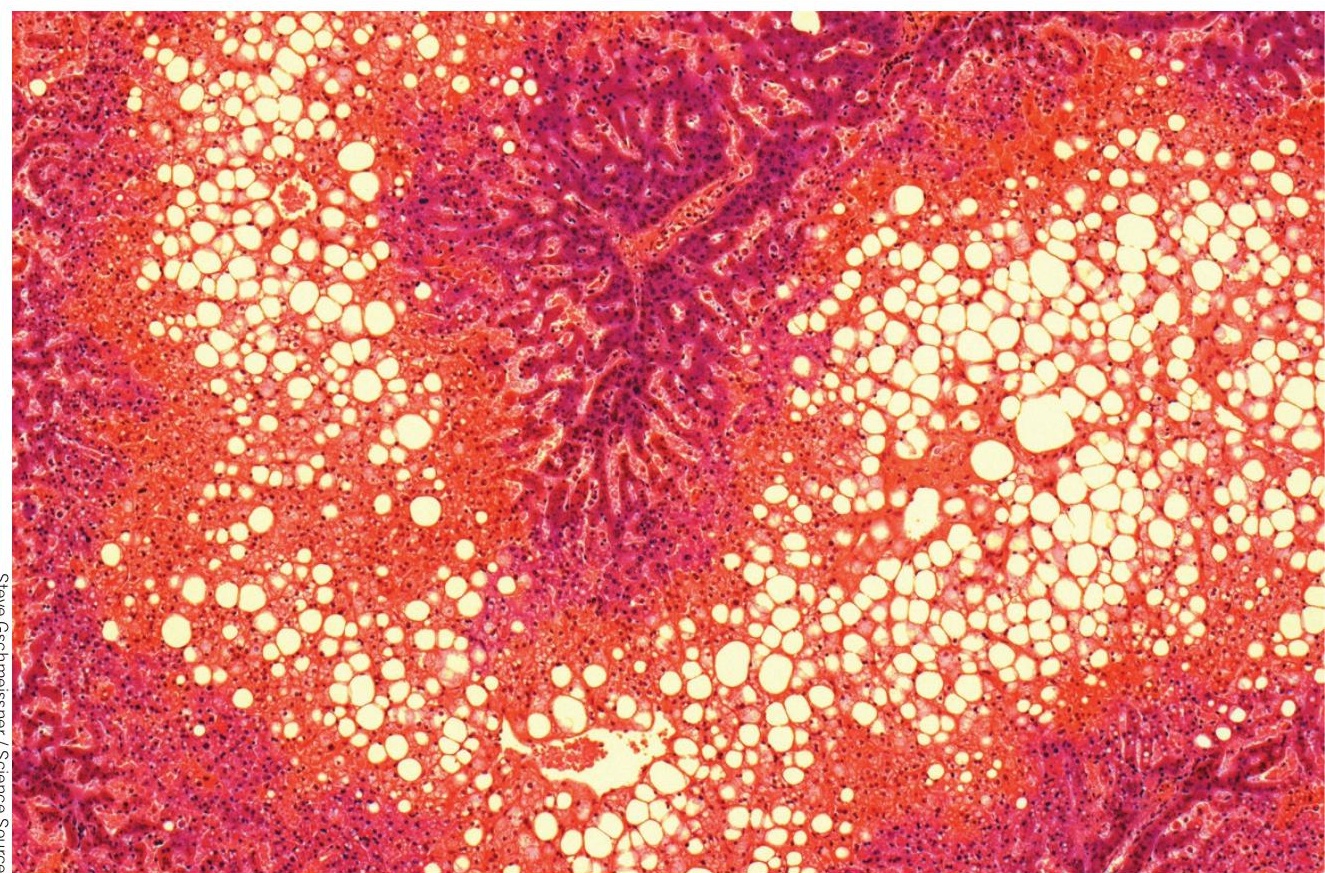

Fatty liver, as it appears in patients with $\mathrm{NASH}$, an indication garnering increasing industry attention due to the ongoing obesity epidemic. progression. By contrast, Gilead Sciences of Foster City, California, Intercept, and Galectin of Norcross, Georgia, all have drugs aimed at reducing or preventing fibrosis. Other experimental drugs aim to improve overall liver function. Lumena's LUM002 acts by preventing bile acid recycling, Tel Aviv-based Galmed's drug aims to reduce fat in the liver, and French biotech Genfit based in Loos, France, aims to develop a drug to both improve liver function and reduce fibrosis.

Which approach renders a drug superior to another remains to be seen. Few data have been released yet, and those that exist are primarily in patients with cirrhosis observed through biopsy but with no clinical manifestations, says Thomas Schiano, professor of medicine at Mt.
Table 1 Compounds in clinical development to treat NASH

\begin{tabular}{lll} 
Company & Product & Stage \\
\hline Gilead Sciences & $\begin{array}{l}\text { Humanized monoclonal antibody simtuzumab } \\
\text { against lysyl oxidase-like 2 (LOXL2) }\end{array}$ & Phase 2b \\
\hline Intercept Pharmaceuticals & Obeticholic acid & $\begin{array}{l}\text { Phase 2b (given FDA fast- } \\
\text { track designation in primary } \\
\text { biliary cirrhosis) }\end{array}$ \\
\hline $\begin{array}{lll}\text { Lumena Pharmaceuticals/Shire } \\
\text { (licensed from Sanofi in 2010) }\end{array}$ & $\begin{array}{l}\text { LUMO02, an oral inhibitor of apical, sodium- } \\
\text { dependent, bile acid transporter }\end{array}$ & $\begin{array}{l}\text { Phase 2 (planned later this } \\
\text { year) }\end{array}$ \\
\hline Conatus Pharmaceuticals & $\begin{array}{l}\text { Emricasan, orally active caspase protease } \\
\text { inhibitor }\end{array}$ & Phase 2 \\
\hline Galmed Pharmaceuticals & $\begin{array}{l}\text { Arachidyl amido cholanoic acid (Aramchol), a } \\
\text { fatty acid-bile acid conjugate }\end{array}$ & Phase 2b \\
\hline Genfit & $\begin{array}{l}\text { GFT505, a dual peroxisome proliferator-acti- } \\
\text { vated receptor alpha/delta (PPAR- } \alpha / \delta \text { ) agonist }\end{array}$ & $\begin{array}{l}\text { Phase 2b (given FDA fast- } \\
\text { track designation in NASH) }\end{array}$ \\
\hline Galectin Therapeutics & GR-MD-02, an inhibitor of galectin 3 & Phase 1
\end{tabular}

Sinai School of Medicine in New York City and principal investigator of a phase 1 trial of Galectin's drug in NASH. Many of these drugs are also being tested as treatments for other liver diseases, and some may be approved in other indications before NASH. But "the need is so great in fatty liver, research is being focused in this area," says Schiano.

Regulatory approval of any drug is likely years away, says Spada. There is no regulatory path for developing a NASH drug. The US Food and Drug Administration (FDA) is currently discussing with companies the clinical endpoints it might accept for a NASH indication, which are complicated by the fact that NASH advances over years. Trials that go on for 5 to 10 years are not feasible, says Spada. "Hopefully FDA will give us some guidance on that soon." FDA is certainly "highly motivated," he adds, "given the skyrocketing rise in NASH incidence."

Lumena's other candidate LUM001, included in the acquisition, was originally licensed from Pfizer, where it was tested as a cholesterollowering drug. The small molecule inhibits the apical, sodium-dependent, bile acid transporter in the small intestine, preventing bile accumulation in the liver. Shire expects to bring LUM001 into phase 2 development for four rare liver diseases. Shire was unable to comment on the deal with Lumena as it was considering an acquisition proposal from AbbVie at the time of filing. Gunjan Sinha Berlin 